\title{
FACTORS AFFECTING POOR ATTENDANCE FOR OUTPATIENT PHYSIOTHERAPY BY PATIENTS DISCHARGED FROM MTHATHA GENERAL HOSPITAL WITH A STROKE
}

\begin{abstract}
Background: Stroke is a major cause of disability in the world and its long term effects require adherence to physiotherapy protocols for optimal rehabilitation. Clinical impression of data from Mthatha General Hospital (MGH) Physiotherapy Department revealed that there was poor attendance of outpatient physiotherapy by stroke patients discharged from MGH and this had negative effects on outcomes and health care costs.

Objective: To determine the extent and the socio-demographic reasons for poor attendance for outpatient physiotherapy by stroke patients.

Methods: An observational descriptive study was conducted using a randomly selected sample of 103 stroke patients from a population of 139 who attended physiotherapy in MGH in 2007. Structured interviews were conducted and SPSS was used for data analysis.
\end{abstract}

Results: The majority (86\%) of patients did not attend physiotherapy until discharge from the Physiotherapy Department. The major reasons for poor attendance were lack of finances (95\%), migration to other areas (36\%), and living a long distance from MGH (38\%).

Conclusion: Almost 9 out of 10 stroke patients fail to attend for outpatient physiotherapy because of lack of finances.

Recommendation: Development of a Provincial Rehabilitation Policy with specific reference to decentralization of rehabilitation services to address unavailability of physiotherapy services at clinics and health care centers which are proximal to the patients' residential areas is recommended.

KEY WORDS: STROKE, REHABILITATION, ADHERENCE, POVERTY, EASTERN CAPE.

\section{INTRODUCTION}

Stroke is one of the major causes of disability in the world (Ju et al. 2007), and its long term effects require good adherence to physiotherapy sessions as an outpatient to ensure optimal rehabilitation. Patients are often left with residual effects of stroke as they are affected differently by the stroke attack (Mc-Murdo 2008). Rehabilitation is critical for most of the recovery

\section{Correspondence Author:}

N.P. Ntamo

Mthatha Hospital Complex,

P.O. Box 1105

Mthatha

5099

Email: preciousntamo@yahoo.com experienced by patients with a stroke (Vega 2009). The aims of the outpatient physiotherapy rehabilitation are to prevent deterioration and promote the re-acquisition of activities of daily living (Gladman et al. 1993). Independent walking function was reported to be a highly desired goal amongst stroke patients (Hale and Eales 2006). Some patients with a stroke can return to work when it is appropriate (Ozet et al. 2006).

On clinical impression, poor attendance for physiotherapy by stroke outpatients was reported by physiotherapists as a serious problem at Mthatha General Hospital (MGH), Eastern Cape province of South Africa. $\mathrm{MGH}$ is one of the institutions that make up Mthatha Hospital Complex which is a referral institution for the eastern part of the Eastern Cape, a mostly deep rural province. Patients who are admitted with a stroke are referred to physiotherapy from the hospital wards for rehabilitation as soon as their medical condition is stabilised. All patients with a stroke received intensive rehabilitation while still admitted in the wards. On discharge from the ward, the stroke patients are advised to return as outpatients for further physiotherapy until they are discharged from the Physiotherapy Department. Their appointments for physiotherapy are once or twice per week for the first to forth month, depending on their condition, which ranges from being partially or fully dependant to a caregiver. Those who were referred from other institutions, they are discharged 
from the wards and referred back to their institutions for further rehabilitation.

\section{Outpatient physiotherapy}

A high proportion of stroke patients deteriorate after discharge from the hospital and early gains from physiotherapy in the hospitals may be lost (Gladman et al. 1993). Pinedo and de la Villa (2001) also observed that after a stroke, patients are at risk of numerous complications after leaving the hospital. Outpatient physiotherapy rehabilitation is crucial in resource constrained countries like South Africa as the length of stay at rehabilitation centers for stroke patients is decreasing due to a variety of factors including increasing costs to the state (Langhammer et al. 2006), and this often leaves the patients with incomplete recovery at discharge. In order to maintain and improve functional gains attained in the hospital, these patients need to attend physiotherapy as outpatients until they are discharged by the physiotherapists. Masaaki (2005) supports the idea of regular attendance of outpatient physiotherapy rehabilitation by stroke patients for better outcomes.

At a global level, most patients with a stroke did not mind attending outpatient physiotherapy although this often consumed a lot of time, this according to the review study by Thomas and Parry (1996) on perspectives of patients with stroke to their rehabilitation. Instead, the patients with a stroke in this study felt that physiotherapy rehabilitation was a way of getting out of the house and meeting different people and also a way of giving relief to caregivers (quoted in Hale et al. 2003). In another study which was conducted in the United States (Barclay 2007), 30\% of stroke survivors reported that they were attending outpatient rehabilitation. In Africa there are limited studies that have been conducted on attendance of physiotherapy by outpatients with a stroke.

\section{HIV and Aids in stroke}

An increased occurrence of stroke in patients with HIV infection has been reported, mainly when the disease is in the advanced stage. Ischemic stroke and intracerebral haemorrhage were reported to be strongly associated with AIDS (Nogueira and Pinto 2005). An increase in life expectancy, going along with the increase in the burden of noncommunicable diseases including stroke in South Africa, is expected with the rollout of highly active antiretroviral therapy (Mayosi et al. 2009). These patients need to be rehabilitated to their maximum potential to facilitate independency and possibly return to work.

A scrutiny of the Outpatient Physiotherapy Department data shows that a large number of stroke patients at MGH did not keep their appointments for physiotherapy as outpatients. Most of defaulting patients returned with different medical complications including spasticity of the affected limb (Savas et al. 2007). The rehabilitation process becomes more difficult and causes physical pain to the patient if structures had not been mobilised for some time. Such patients do not get maximum benefit from physiotherapy because of the poor attendance of physiotherapy sessions. This is a serious challenge to physiotherapy staff as it becomes difficult to monitor the progress of the patients and to take them to the next phase of care and ensure that the patients are rehabilitated to their maximum potential. The ultimate impact of non-adherent patients becomes a serious resource burden to an already constrained health service and society at large. For the purpose of this study, patients had to attend at least $70 \%$ of their outpatient physiotherapy sessions to be considered adherent. This study's aim was to fill a gap in the body of knowledge in this subject by describing the extent and the sociodemographic factors that affected poor attendance for return physiotherapy sessions by outpatients with a stroke, after being discharged.

\section{METHODS}

Ethical approval to conduct the study was obtained from Walter Sisulu University Ethics committee (Ref. 0018/09). This study used an observational, descriptive, cross-sectional study design. Both qualitative and quantitative data collection methods were used to ensure quality and reliability of the study
(Weinreich, 2006). The study population consisted of 139 outpatients with a stroke who attended physiotherapy in Mthatha General Hospital from January 2007 to December 2007. The sample size was 103 patients. The patients were selected using simple random sampling method whereby a number from 1 to 139 was assigned to each patient in the study population and placed in a bowl from which 103 patients were randomly selected. Structured interviews were conducted to collect data. The researcher had a predetermined list of questions for all patients and a uniform way of recording the responses in the space provided for such. The questions were adapted from Section 5 of the Stroke Performance Measurement Implementation Guide (2008). The structured interviews were considered to be the most suitable measuring instrument for the stroke patients who would not be able to write properly and for a rural community which is mostly illiterate. Closed-ended questions were used for clear and specific answers and open-ended questions were used to allow for true reflection of opinions and feelings of patients. Records of 103 patients with a stroke who received physiotherapy from January to December 2007 were reviewed from the Physiotherapy Department to get information on the details of their demographics; where they lived; contact numbers and close relatives of patients. Home visits were conducted and in situations where patients were not available at the registered addresses, names and addresses and contact numbers of close relatives from the hospital records were utilised to assist in locating the patients. Local headmen were also approached for assistance in locating patients in villages. Patients were visited in their places of residence to allow for comfort and relaxation during the interviews. Where patients had difficulty in answering questions, care givers were asked for assistance. The interviews were conducted in both English and Xhosa, which-ever was more appropriate. Records of responses from patients with a stroke were counted to ensure that all expected responses were received. Raw data was entered 
into a summary table and coded. All qualitative responses were categorized into common themes and quantified. Qualitative data was analysed manually with a word processing program. Quantitative data was summarized using the descriptive statistics. SPSS was used to analyse data in order to show proportions and frequencies so as to determine how the patients with a stroke responded to questions in their interviews.

\section{RESULTS}

Of the 103 sampled patients, 85 participated in the study, giving a response rate of $82 \%$. All patients were hemiplegic as a result of the stroke. Of the 18 patients who did not participate in the study, six patients were not traceable at the stated addresses, nine patients had died since they were discharged from the hospital with a stroke, and three patients declined to participate in the study.

Of the 85 patients with a stroke who were given an appointment to attend the Physiotherapy Department for continued outpatient rehabilitation, 43 $(51 \%)$ were females and $42(49 \%)$ males. The number of patients in the 20 -44 years group was higher $(35 \%)$ than in the other age groups (Figure 1). The mean age was 46.4 years $(42.4-50.3)$ $(\mathrm{SD}=18.8)$. The majority of patients $(95 \%) \quad(n=81 / 85) \quad$ were unemployed (Table 1). The distances between the stroke patients' homes and MGH varied widely, $27 \%$ were more than $100 \mathrm{~km}$ away from MGH (Table 2).

\section{Physiotherapy as an out - patient}

Ninety four percent $(n=80 / 85)$ of patients were given appointments to come back to $\mathrm{MGH}$ as outpatients whilst the remaining $6 \%(n=5 / 85)$ were referred to nearby Mbekweni Health Center. The majority of patients (96\%) $(n=77 / 80)$ kept their first appointment for physiotherapy as outpatients. Figure 2 illustrates the adherence of patients to physiotherapy until they were discharged from the Physiotherapy Department. The percentage of defaulters $(86 \%)(n=73 / 85)$ includes the five patients who were referred to Mbekweni since they were supposed to return to

Table 1: Employment status of patients $(n=85)$

\begin{tabular}{|l|l|l|}
\hline Status of employment & N & $\%$ \\
\hline Employed & 4 & 5 \\
\hline Not employed & 81 & 95 \\
\hline Total & 85 & 100 \\
\hline
\end{tabular}

Table 2. Patients $(n=85)$ with distances from hospital

\begin{tabular}{|l|l|l|}
\hline Distance from MGH & $\mathbf{n}$ & $\%$ \\
\hline $0-25 \mathrm{~km}$ & 25 & 29 \\
\hline $26-50 \mathrm{~km}$ & 28 & 33 \\
\hline $51-75 \mathrm{~km}$ & 6 & 7 \\
\hline $76-100 \mathrm{~km}$ & 3 & 4 \\
\hline$>100 \mathrm{~km}$ & 23 & 27 \\
\hline
\end{tabular}

Table 3. Reasons of patients $(n=30)$ for returning to physiotherapy for rehabilitation at Mthatha General Hospital.

\begin{tabular}{|l|l|l|}
\hline Reason for returning & N & $\%$ \\
\hline To consult a doctor & 15 & 50 \\
\hline To fix wheel chair or walking aid & 11 & 37 \\
\hline when there was money & 4 & 13 \\
\hline Total & 30 & 100 \\
\hline
\end{tabular}

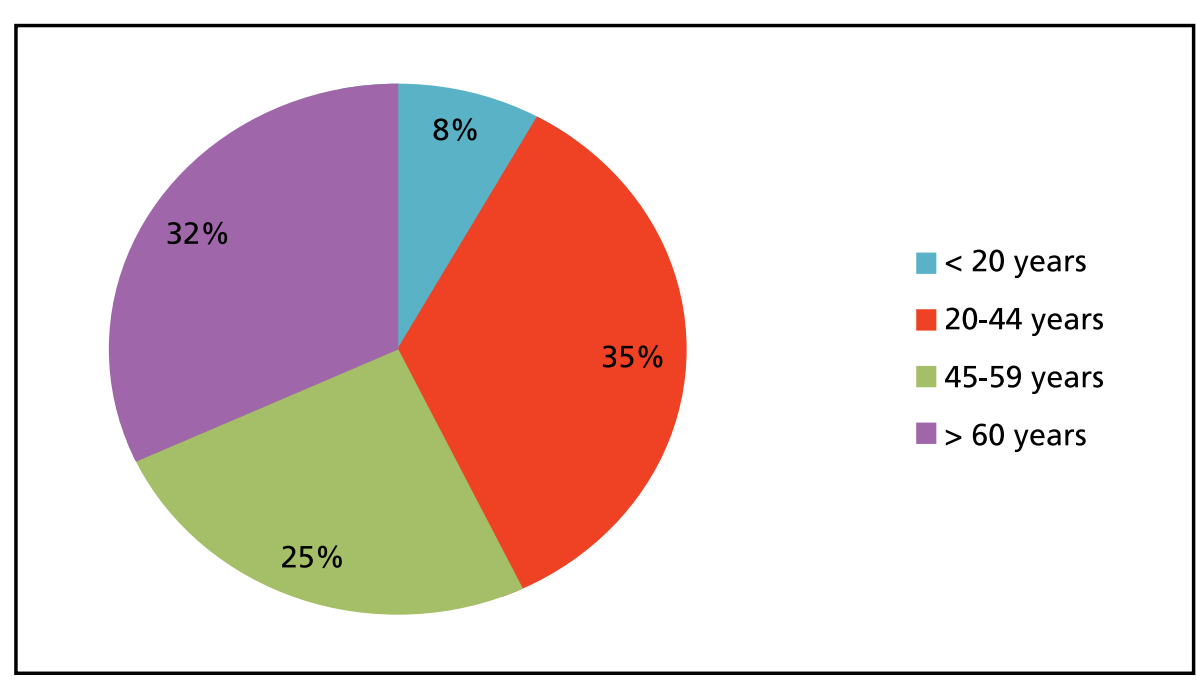

Figure 1: Age distribution of patients with a stroke $(n=85)$ attending physiotherapy for rehabilitation.

MGH because physiotherapy services at Mbekweni where they were referred to were closed. Of the 73 patients who defaulted physiotherapy, 43 never came back to Physiotherapy Department. Of the 30 patients who returned to physiotherapy, 87\% $\quad(n=26 / 30) \quad$ came to physiotherapy because they were in MGH for other reasons (Table 3).
A wide variety of reasons responsible for poor attendance of physiotherapy were identified (Figure 3), but the main reasons were distance from $\mathrm{MGH}$ and lack of finances. Figure 4 demonstrates the condition of stroke patients since they were discharged from the hospital wards, with majority $(50 \%)(n=47 / 94)$ having regressed. 


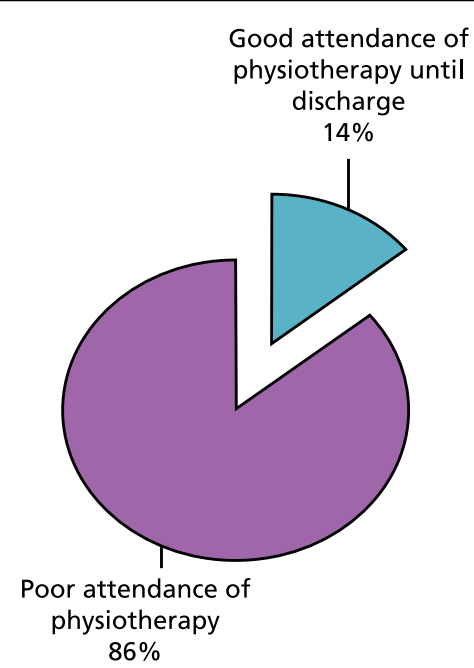

Figure 2: Adherence to physiotherapy until discharge by patients with a stroke $(n=85)$.

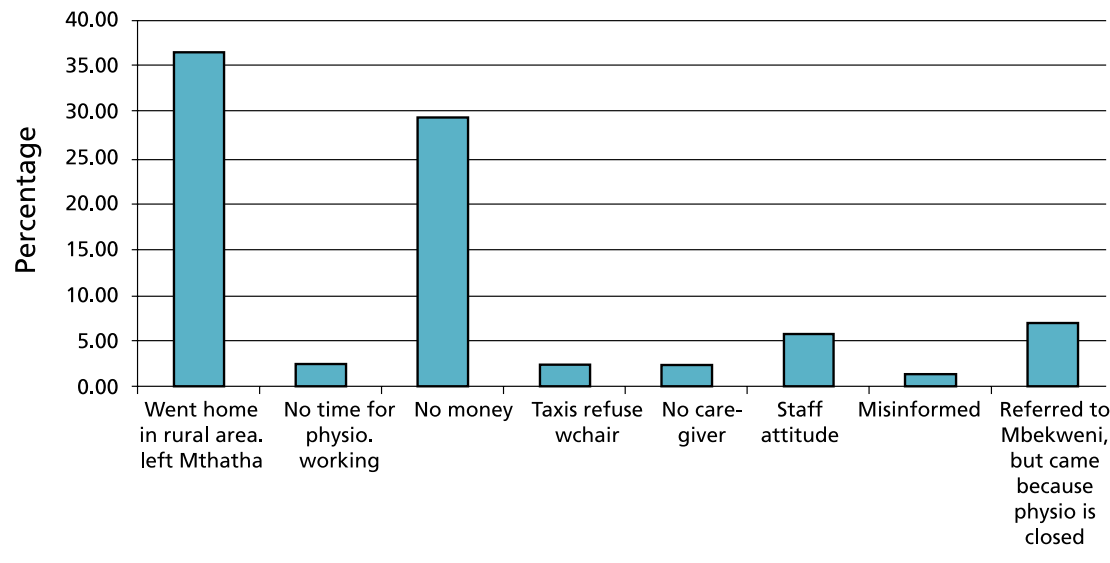

Reasons

Figure 3: Reasons for poor attendance by patients with a stroke $(n=73)$.

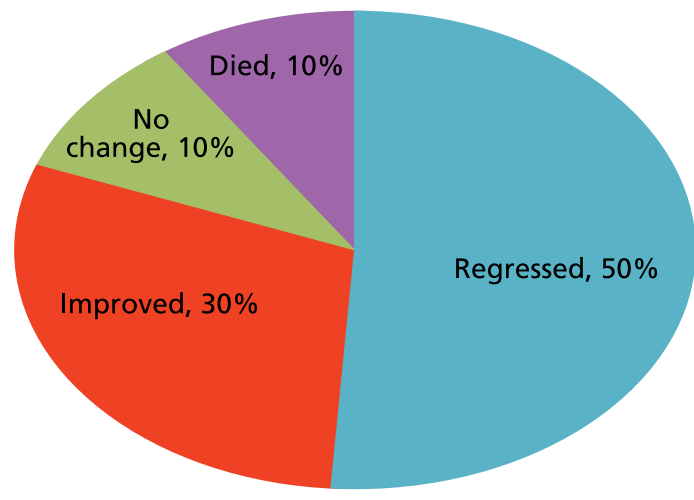

Figure 4: Condition of patients with a stroke $(n=94)$ since discharge.

\section{Family income}

It was evident from the responses that the majority of patients were breadwinners who depended on government social security grant to support their families. This was supported by following the responces from patients, "I was providing for my family before I got sick because I was working. Now I am not working because I am sick. I receive a disability grant for my sickness which is helping to put food on the table for my family". "There is no person working now since I came back from Gauteng because of stroke. My daughters cannot find jobs although they passed grade 12. We are dependent on the disability grant I am getting for my stroke" (responded one patient). The child support grant was a means of support for some families as supported by the following response from the wife of a patient who could not express himself properly due to a stroke, "The child support grant for my 2 children and 1 grandchild is our source of income at the moment as we are still waiting for the response from the social workers for the application for the disability grant for my husband".

The effect of geographic distribution on attendance of physiotherapy

The majority of patients with a stroke were from rural areas and it was difficult for these patients to keep regular physiotherapy appointments, as supported by the following responses from patients: "I stay at Ncise Administrative Area. I have to take two taxis to MGH; one from my village to the tar road and the other from the tar road to $M G H$. It is difficult to go to MGH every time I am expected to go". "I left my shack at Mandela Informal Settlement since I got sick and came back home to be cared for by my relatives. As you can see this is deep rural and far from MGH. I cannot attend physiotherapy now because it is far for me, but I enjoy it here because I stay with my relatives" (responded one patient). It was evident from the responses that most patients who resided in the areas around Mthatha attended physiotherapy until they were discharged from the Physiotherapy Department, as supported by the fol- 
lowing responses: "Yes, I went to physiotherapy until my physiotherapist stopped me because I stay just down the road at Blakeway Street." "I attended physiotherapy until I was discharged, because I wanted to get better. My son and daughter in law would take me to physiotherapy and watch me doing the exercises. I still do the exercises even now and if I have problems I still go to physiotherapy. I do not even call my son to come and fetch me anymore; I take the local Ngangelizwe taxis because it is not far" (responded one patient).

\section{Reasons for poor attendance}

Qualitative reasons of patients with a stroke for poor attendance of physiotherapy differed depending on their circumstances. The examples of different responses were as follows: "My sister who stays in Kwezi Township in Mthatha took care of me when I suffered stroke, but I came back to my rural home when I felt better. I gave the address of Kwezi so that I get managed at MGH until I get better. I did not want to be sent back to Siphethu Hospital because sometimes the medication gets finished. I experienced problems with physiotherapy when I had a knee injury last year because when the physiotherapy assistant who is working there was away I was not attended to and their bicycle was not working. MGH is far for me to attend physiotherapy regularly now that I am here. When I go for my medication at MGH, I also go for physiotherapy". "I do not have time to go to MGH for physiotherapy because I have a fruit stand in town which helps me to take care of my family because I am a single mother. The child support grant is too little for my family's needs" (responded one patient). "I need assistance when I have to travel. My grand children whom I stay with are attending school. I do not have any other person to assist me" (responded one patient).

\section{DISCUSSION}

In this study the age distribution of stroke patients particularly among young adults was consistent with the findings of Igumbor and Buso (2006) who noted that in the Eastern Cape stroke is among the 10 leading causes of admissions among the young adults $(20-44$ years $)$. The number of female patients was similar to those of male patients. This is in contrast to a study by The Southern African Stroke Prevention Initiative which found that the stroke prevalence was higher in females $(348 / 10000)$ than males (246/100 00) (Connor and Bryer 2009).

The majority of patients in this study lived in rural areas which were distant from MGH. They had to travel long distances to come for physiotherapy. Of great concern was the $27 \%(n=23 / 85)$ of patients who were residing in areas over $100 \mathrm{~km}$ from MGH. This implied that they had to spend a lot of money for transport to come to $\mathrm{MGH}$ for physiotherapy treatment. Although there were district hospitals proximal to where they lived, these patients were reluctant to utilise the nearest hospital physiotherapy services because of poor resources in terms of equipment and human in these institutions.

Unemployment is a huge problem in the Eastern Cape particularly in Transkei (Punt et al. 2005). Given the fact that an overwhelming majority of patients were unemployed, this meant that they were financially challenged and could not afford attending physiotherapy at a distant MGH. The few patients who attended physiotherapy until they were discharged from the physiotherapy department were patients who were staying in locations in and around $\mathrm{MGH}$. These findings were consistent with Barclay (2007) where the prevalence of outpatient stroke rehabilitation was higher in people who lived in the center of metropolitan areas. The majority of patients did not attend physiotherapy until their condition was sufficiently stable to not need further rehabilitation. These were mostly patients who stayed in rural areas away from MGH. Most of them never came back to physiotherapy at all. Some patients returned to the Physiotherapy Department only when they came to collect their medication from the hospital, often about a month after discharge. Some patients came when the assistive device that they had been issued with malfunctioned. The condition of the majority of patients from this group deteriorated since discharge from the ward. Reasons that might contribute to the regression include lack of functional exercises of the affected side (Savas et al. 2007).

There are limited studies available on attendance of physiotherapy by outpatients with a stroke. The main reasons for poor attendance of physiotherapy by outpatients with a stroke were that patients from rural areas who were staying with close relatives in Mthatha or renting/owning shacks in informal settlements around Mthatha when they suffered stroke tend to go back to their homes in rural areas on discharge. The residential address given on admission was usually the one for Mthatha not the address of the real rural home. The reason for this was the fear of being down referred to the rural institution proximal to the patient, where the resources were inadequate. However, once they were stabilized or condition improved, patients usually tend to go back to their familiar surroundings, or if not to die peacefully at their rural home among their ancestors. Once they went home, it was difficult for these patients to attend physiotherapy as required by the physiotherapists because it was far and they had serious financial constraints. For the majority of these patients the government grant (disability/ old age/ child support) was the only source of income for the whole family. Even those patients from villages around Mthatha could not attend physiotherapy until they discharged from the Physiotherapy Department as they were also financially challenged. Self employed patients indicated that they did not have time to attend physiotherapy for fear of losing income as they were breadwinners of their families. These patients were hawkers who could gain more strength and range of movement of the affected limb from regular outpatient physiotherapy, and thus improvement in performance in their jobs. Absence of care-givers or assistance was highlighted by some patients as the reason for poor attendance. Grandchildren were acting as care-givers for some of these patients and were at school during the day. Insensitive public transport system especially taxi drivers who refused to transport patients 
with wheelchairs on their vehicles was a serious challenge for some of the patients who were in no situation to afford private transport. Urimubensho and Rhoda (2011) also highlighted lack of transport as a challenge experienced by unemployed patients with a stroke to attend outpatient physiotherapy. Bad attitudes from hospital staff identified in this study is a common problem in public health institutions, often cited as contributing to poor public health quality care. The nature of bad attitudes ranged from being spoken to rudely by hospital staff for refusing to take hypertension treatment for whatever reason including religion. These findings were consistent with Gibbon (1991) and Maclean et al. (2002) where negative attitudes of hospital staff towards patients with a stroke were reported to be demotivating for rehabilitation. The closure of physiotherapy services at Mbekweni due to staff shortage, which was thought to have physiotherapy services created confusion for patients who were referred there. These patients had to go back to MGH only when they had money.

\section{STUDY LIMITATIONS}

The limitations that were experienced by the researcher of this study were as follows:-

- The patients selected for this study may not be representative of the population of patients with a stroke since the researcher looked at those patients who were given appointments for physiotherapy on discharge from the wards, consequently the results may not be generalized to the entire population.

- The instrument that was used to collect data was a limitation as the researcher depended solely on the responses given by the patients. There was no way of verifying if the patient lied.

\section{CONCLUSION}

There were a number of reasons for poor attendance for physiotherapy by patients with a stroke but the major socioeconomic reasons identified were lack of finances, migration, and the distance from MGH. We recommend the development of a provincial decentralization policy which will ensure creation and filling of physiotherapy positions in health centers and clinics. We also recommend that the Eastern Cape Department of Health should ensure that the Physiotherapy Departments of the district hospitals are revitalised to ensure that adequate space and latest technology equipment in these departments are available as these are currently inadequate in most district hospitals in rural areas and the situation of patients who are defaulting physiotherapy has not changed. The impact of the poor attendance for physiotherapy by patients with a stroke on the number of disabilities and the burden of care to the health service needs further research.

\section{REFERENCES}

Barclay L 2007 More than $30 \%$ of US stroke survivors receive outpatient rehabilitation. Morbidity and Mortality Weekly Report 56: 504-507.

Connor M, Bryer A 2009 Stroke in South Africa. South African Medical Research Council (Online) Available: http:/www.mrc.ac.za/chronic/cd/chapter14/pdf (26 October 2009).

Gibbon B 1991 A reassessment of nurses' attitudes towards stroke patients in general medical wards. Journal of Nursing 16: 1336-1342.

Gladman JRF, Lincoln NB, Barer DH 1993 A randomized controlled trial of domiciliary and hospital-based rehabilitation for stroke patients after discharge from hospital. Journal of Neurology, Neurosurgery, and Psychiatry 56: 960-966.

Hale LA, Eales CJ 2006 Recovery of walking function in stroke patients after minimal rehabilitation. Physiotherapy Research International 3: 194-205.

Hale L, Bennet D, Bently M, Crawshaw A, Davis H 2003 Stroke Rehabilitaion-Comparing hospital and home-based physiotherapy: the patient's perspective. New Zealand Journal of Physiotherapy 31:84-92

Igumbor EU, Buso DL 2006 The increasing early showing of non-communicable diseases in the health profiles of South Africans. South African Family Practice 48: 4-5.

Ju MS, Lin CCK, Chen SM, Hwang IS, Kung PC, Wu ZW 2007 Applications of robotics to assessment and physical therapy of upper limb of stroke patients. Sciyo.com (Online) Available: http://sciyo.com/artcles/show/title/applicationsof-robotic-to-assessment-and-physical-therapy-ofupper-limb-of-stroke-patients. (16 July 2009).
Langhammer B, Lindmark B, Stanghelle JK 2006 Stroke patients and long- term training: is it worthwhile. Clinical Rehabilitation 21: 495-510.

Maclean N, Pound P, Wolfe C, Rudd A 2002 The concept of patient motivation: A qualitative analysis of stroke professionals' attitudes. Stroke 33:444-448.

Masaaki, O. 2005. Cardiovascular fitness of post-stroke patients. International Journal of Rehabilitation Research, 28(3): 285-288.

Mayosi, B.M. Flisher, A.J. Lallo, U.G. Sitas, F. Tollman, S.T. and Bradshaw D. 2009. The burden of non-communicable diseases in South Africa. Lancet. 374(4): 942

Mc Murdo M 2008 Stroke (Cerebrovascular accident)(Online) Available: http://www.netdoctor. co.uk/diseases/facts/stroke.htm (17/01/2009).

Nogueira A, Pinto MD 2005 Aids/HIV infection and Cerebrovascular Disease. Seminars in Cerebrovascular Diseases and Stroke 5: 40 - 46.

Ozet PDF, Makeleler B, Posta YE, Posta EE 2006 The relationship between type of stroke and complications and rehabilitation outcomes. Trakya University. (Online) Available: http://www.tutfd. org/text.php ( 12 May 2009).

Pinedo S, de la Villa FM 2001 Complication in the hemiplegic patient in the first year after a stroke. Public Medline (Online) Available: http://www. ncbi/nlm/nih/gov(15/02/2009).

Punt C, Pauw K, Schoor M, Nyhodo B, Mcdonald S, Chant L, Valente C 2005 A profile of the Eastern Cape province: Demographics, poverty, inequality and unemployment. Provide project 1: 7-19.

Savas S, Akkus S, Soyupek FC, Ilgun E, Yildiz S 2007 Impact of delayed initiation to stroke rehabilitation on functional outcomes and medical complications. Turkish Journal of Physical Medicine and Rehabilitation 53:45-49.

Stroke Performance Measurement Implementation Guide. 2008. (Online) Available: http://www. jointcommission.org/assets/1/18/1-section 7 . $\operatorname{pdf}(02$ Feb 2011).

UrimubenshoG, Rhoda A 2011 Environmental Barriers experienced by stroke patients in Musanze district in Rwanda: a descriptive qualitative study. African Health Sciences 11:398-405.

Vega J 2009 Stroke rehabilitation is a critical part of stroke recovery. Stroke (Online) Available: http://stroke.about.com/od/livingwithstroke/a/ livingwithstroke.htm (11 September 2009).

Weinreich, N. K. 2006. Integrating Quantitative and Qualitative Methods in Social Marketing Research. (Online) Available: http://www.socialmarketing.com/research.html (22 August 2010). 